\title{
LITTER DECOMPOSITION ON FOREST ROADS VERSUS INSIDE TROPICAL RAINFORESTS IN SABAH, MALAYSIA
}

\author{
Yoshida $\mathrm{T}^{1, *}$, Hasegawa $\mathrm{M}^{2}$, Ito $\mathrm{MT}^{3}$, Kawaguchi $\mathrm{T}^{4}$, Seino $\mathrm{T}^{5}$, Chung $\mathrm{AYC}^{6} \&$ Kitayama $\mathrm{K}^{7}$ \\ ${ }^{1}$ Field Science Center, Faculty of Agriculture, Tokyo University of Agriculture and Technology, Fuchu, Tokyo 183-8509, Japan \\ ${ }^{2}$ Forestry and Forest Products Research Institute, Shikoku Research Centre, Kochi, Kochi 780-8077, Japan \\ ${ }^{3}$ Faculty of Economics and Management, Surugadai University, Hannou, Saitama 357-8555, Japan \\ ${ }^{4}$ Soil Ecology Research Group, Graduate School of Environmental and Information Sciences, Yokohama National University, \\ Yokohama, Kanagawa 240-8501, Japan \\ ${ }^{5}$ Agricultural and Forestry Research Center, Graduate School of Life and Environmental Sciences, University of Tsukuba, \\ Tsukuba, Ibaraki 305-8577, Japan \\ ${ }^{6}$ Forest Research Centre, Sabah Forestry Department, P.O. Box 1407, 90715 Sandakan, Sabah, Malaysia \\ ${ }^{7}$ Graduate School of Agriculture, Kyoto University, Kyoto, Kyoto 606-8502, Japan
}

*yoshitom@cc.tuat.ac.jp

Submitted October 2017; accepted April 2018

\begin{abstract}
Forest roads constructed by bulldozers change the physical environment within the forests. A litter-bag experiment using three substrates (wood blocks, and Shorea and Macaranga leaf litter) was performed to clarify the effects of forest roads on initial litter decomposition in tropical rainforests. The results showed that the wood blocks and leaf litter had different decomposition rates between locations (on the path vs. inside the forest). The wood blocks decomposed more slowly on the path than inside the forest, whereas Shorea leaf litter decomposed more quickly on the path than inside the forest. The lower moisture content of both Shorea and Macaranga leaf litter indicated a more pronounced drought condition on the path. The surface area of leaf litter decreased more in Macaranga than in Shorea, whereas the leaf mass per area showed the opposite trend. This findings suggested that Macaranga leaf litter mainly decomposed by fragmentation, whereas Shorea leaf litter mainly decomposed by microbial degradation and leaching, in addition to fragmentation. The results indicated that road disturbance changed the balance between fragmentation and other degradation processes. The findings also highlighted that assessing the loss of surface area and leaf mass per area is appropriate for evaluating the influence of different types of leaf litter decomposition.
\end{abstract}

Keywords: Leaf area, leaf mass per area, litter bags, road disturbance, skid trails

\section{INTRODUCTION}

Forest roads (e.g., logging roads and skid trails constructed by bulldozers) are linear disturbances that separate continuous forests in to smaller fragments, and change their physical environments (Laurance et al. 2009). The use of bulldozers increases soil compaction, which in turn, decreases infiltrability and root penetrability resulting in soil erosion of the running surface after rainfall (Malmer \& Grip 1990, Sidle et al. 2004, Makineci et al. 2007). In tropical rainforests, soil erosion on roads is severe because of high rainfall intensities (Wallin \& Harden 1996, Laurance et al. 2009). These environmental conditions on forest roads limit the recovery of plants and ground-dwelling invertebrate communities (Guariguata \& Dupuy
1997, Pinard et al. 2000, Vasconcelos et al. 2000).

These impacts of forest roads also affect litter decomposition, which is controlled by macro- and microclimate, decomposing organisms, and litter quality (Coûteaux et al. 1995). Road disturbances cause a decline in the contents of soil organic matter and nutrients and result in an increase in temperature and a decrease in microbial activity on and around roads (Uhl et al. 1982, Ilstedt et al. 2006, Delgado et al. 2007, Makineci et al. 2007). These abiotic and biotic changes result in slower litter decomposition (Barlow et al. 2007). In tropical forests, in addition to microorganisms, litter-feeding invertebrates, including termites and isopods, also play a major role in litter 
decomposition (Yamashita \& Takeda 1998, González \& Seastedt 2001). Road disturbance likely alters how these invertebrates affect litter decomposition by changing their community composition.

Fragmentation by litter-feeding invertebrates and abiotic processes, such as drying, wetting and surface water flow on the ground, decrease the surface area of leaf litter (Anderson 1973, Swift et al. 1979). In contrast, the surface area is maintained during degradation by microorganisms and the leaching of soluble substrates in the early stages of litter decomposition. Osono et al. (2009) evaluated the differences in the decomposition processes in a tropical forest between sun-bleached portions that were colonized by fungi and non-bleached portions of leaf litter by measuring the leaf mass per area. Therefore, the proportion of remaining leaf litter surface area and leaf mass per area are useful indices for roughly separating the types of decomposer functioning in the early stages of litter decomposition.

This study aimed to clarify the effects of forest roads on initial litter decomposition in tropical rainforests. A litter-bag experiment was conducted using the leaf litter of Shorea and Macaranga, which are the dominant and pioneer tree genera in the study region (Slik et al. 2003, Imai et al. 2012), as well as commercial wood material. It was predicted that (1) wood blocks and leaf litter would decompose more slowly on forest roads (bulldozer paths) than inside the forest; and (2) Shorea and Macaranga leaf litter would have different decomposition rates, because these genera are known to differ in their physical and chemical characteristics (Hirobe et al. 2004).

\section{MATERIALS AND METHODS}

\section{Study sites}

The study was conducted in Deramakot Forest Reserve and the neighboring Tangkulap Forest Reserve, Sabah, Malaysia $\left(5^{\circ} 14^{\prime}-5^{\circ} 30^{~ ' N, ~} 117^{\circ}\right.$ $\left.11^{\prime}-117^{\circ} 36^{\prime} \mathrm{E}\right)$, which are subject to different forest management practices. This region has an equatorial tropical humid climate. The annual rainfall at this site averages approximately $3,100 \mathrm{~mm}$, and the mean annual air temperature is $25^{\circ} \mathrm{C}$, based on data from 2008 to 2010 . Both Deramakot $\left(551 \mathrm{~km}^{2}\right)$ and Tangkulap $\left(275 \mathrm{~km}^{2}\right)$ are composed of lowland mixed dipterocarp tropical rainforests that were selectively logged from the 1950s to the 1980s (Lagan et al. 2007, Ong et al. 2013).

The study areas have three forest types: pristine $\left(5^{\circ} 22^{\prime} \mathrm{N}, 117^{\circ} 25^{\prime} \mathrm{E}\right)$, reduced-impact logged (RIL) $\left(5^{\circ} 21^{\prime} \mathrm{N}, 117^{\circ} 25^{\prime} \mathrm{E}\right)$, and conventionally logged (CL) forests $\left(5^{\circ} 24^{\prime} \mathrm{N}, 117^{\circ} 18^{\prime} \mathrm{E}\right)$. The pristine forest had some evidence of mild logging activities (e.g. old bulldozer paths and old stumps) in the past before they were conserved in the 1980s. The RIL is a kind of selective logging that requires detailed tree inventories, such as locations, species names and size (biomass) of the trees, and it reduces soil damage through well-planned construction of logging roads and skid trails (Bertault \& Sist 1997, Putz et al. 2008). The section of RIL forest that was used in this study was conventionally logged once between the 1950 s and the 1980 s, and then by reducedimpact logging once in 1995. The CL forest was harvested by unregulated selective logging at least twice before 2001 (Langner et al. 2013). For details of the study sites and forest management practices, see Lagan et al. (2007) and Ong et al. (2013).

Several skid trails were constructed by bulldozers or crawler tractors in the late 1980 s in the pristine forest and in the 1990s in each section of the RIL and CL forests. Skid trails are generally used as corridors to transport cut $\log$ s from the points of felling to log landings or logging roads during active logging (Buckley et al. 2003, Sidle et al. 2004). These bulldozer paths in the three forests were narrow (2.5-4.0 $\mathrm{m}$ wide), and the canopies above the paths were closed by the elongation of branches from the edges of path after road construction. There was much fallen litter on the paths, but the soil was compacted by the machinery.

\section{Litter-bag experiment}

Litter bags $(20 \mathrm{~cm} \times 20 \mathrm{~cm})$ made of nylon netting with a $4 \mathrm{~mm} \times 2 \mathrm{~mm}$ diamond-shaped mesh was used. Naturally senesced leaves of Shorea macroptera and Macaranga sp. were collected under the canopy of each tree species in March 2006. Dried wood blocks $(2 \mathrm{~cm} \times 3 \mathrm{~cm} \times 4 \mathrm{~cm})$ of Magnolia hypoleuca were also used, purchased in Japan. These substrates were air-dried until their weights stopped decreasing further in the laboratory and the initial weight was measured 
to the nearest $0.01 \mathrm{~g}$. The initial weight of Shorea and Macaranga leaf litter ranged from 0.51$1.58 \mathrm{~g}, 1.10-4.59 \mathrm{~g}$ and $3.42-6.34 \mathrm{~g}$, respectively. The three types of materials (Shorea leaf, Macaranga leaf, wood block) were separated into three litter bags. To clarify the effects of fragmentation by litter-feeding invertebrates and abiotic processes, the surface area of each leaf was measured using Image J v. 1.37, based on a digital image of the leaf (Rasband 2007).

Two quadrats $(2 \mathrm{~m} \times 2 \mathrm{~m})$ were established in a pristine and RIL forest in Deramakot, and a CL forest in Tangkulap. One quadrat was established on a bulldozer path and the other was established inside the forest $(20 \mathrm{~m}$ from the edge of the path). In March 2006, 10 litter bags each of S. macroptera leaf litter, Macaranga sp. leaf litter and wood blocks were placed in each quadrat of each forest. All the litter bags were retrieved in September 2006 (6 months later). The leaf litter and wood blocks in the bags were weighed before (wet mass) and after air-drying (dry mass), and the surface area of the leaf litter samples was also measured. Moisture content (\%) of leaf litter was calculated gravimetrically as follows: moisture content $=[($ wet mass - dry mass $) /$ dry mass $] \times$ 100.

\section{Data analysis}

The degree of decomposition was expressed as the proportion $(\%)$ of the final to the initial leaf litter and wood-block mass, leaf surface area and leaf mass per area that was lost after 6 months. The degree of drought condition is also expressed by the moisture content of leaf litter at the sampling time (6 months later). Generalised linear mixed models (GLMMs) with Gaussian error distributions were used to clarify the effects of location (on the path vs. inside the forest) and tree species (Shorea vs. Macaranga leaf litter) on the proportions of remaining mass and surface area of leaf litter after logit transformation (Warton \& Hui 2011). When the proportion of the remaining leaf surface area exceeded 1 , the value was assumed to be 1 , and the logit transformation was conducted after adding the minimum value of the proportion in the treatment. Because leaf mass per area and leaf moisture content could exceed $100 \%$, logit transformation was not used for these values. The proportions of leaf mass and area, leaf mass per area and leaf moisture content were used as response variables, location and tree species as the explanatory variables, and the study forests as a random effect. The GLMMs was also used to clarify the effects of location on the proportion of remaining mass of wood blocks after logit transformation. The lmer function within the lme4 package in $\mathrm{R}$ v.3.1.3 was used (R Development Core Team 2017). Model comparisons were conducted based on Akaike's information criterion (AIC) values. Models with the lowest AIC values were considered as the best fit in each analysis.

\section{RESULTS}

The AIC values of both the final mass $(\mathrm{g})$ and surface area $\left(\mathrm{cm}^{2}\right)$ of leaf litter were the lowest in the species $\times$ location interaction between the path and inside the forest (Table 1). The final leaf mass and surface area of Shorea was smaller on the path than inside the forest, while those of Macaranga were not different between locations (Figure 1a, b, Table 1). The AIC value of the final leaf mass per area $\left(\mathrm{g} \mathrm{cm}^{-2}\right)$ was the lowest in the model using species as an explanatory variable (Table 1), and thus the leaf mass per area decreased more in Shorea than in Macaranga (Figure 1c). The moisture content of leaf litter was lower on the path (Shorea, 147.5\%; Macaranga, $57.1 \%$ ) than inside the forest (Shorea, $252.5 \%$; Macaranga, $182.1 \%$ ) (Table 1, Figure 2). The AIC values of final mass $(\mathrm{g})$ of wood block were the lowest for location (GLMM, AIC: null model $=121$, location $=113)$, and the mean remaining mass of wood blocks was higher on the path $(79.2 \%)$ than inside the forest $(64.7 \%)$ (Figure 3).

\section{DISCUSSION}

The three substrates (wood blocks, and leaf litter of Shorea and Macaranga) had different decomposition patterns at different locations in the early stage of decomposition. The wood blocks decomposed more slowly on the path than inside the forest, whereas Shorea leaf litter decomposed more rapidly on the path than inside the forest, and Macaranga leaf litter had similar decomposition rates at both these locations. The lower moisture content of both Shorea and Macaranga leaf litter indicated a more pronounced drought condition on the path and lower activity of microorganisms. Ilstedt et 
Table 1 Comparison of delta AIC values and coefficients (coef.) among the models for remaining proportions of the mass $(\mathrm{g})$, surface area $\left(\mathrm{cm}^{2}\right)$, mass per area $\left(\mathrm{g} \mathrm{cm}^{-2}\right)$ and moisture content $(\%)$ of leaf litter using species (Shorea and Macaranga), location (inside the forest and on the path), and their interactions as explanatory variables

\begin{tabular}{|c|c|c|c|c|c|c|c|c|}
\hline & Mass & Coef. & Area & Coef. & $\begin{array}{c}\text { Mass } \\
\text { per area }\end{array}$ & Coef. & $\begin{array}{c}\text { Moisture } \\
\text { content }\end{array}$ & Coef. \\
\hline Null & 7 & & 47 & & 33 & & 51 & \\
\hline Species & 5 & & 29 & & $\mathbf{0}$ & -0.30 & 38 & \\
\hline Location & 9 & & 35 & & 36 & & 18 & \\
\hline Species + location & 6 & & 15 & & 3 & & $\mathbf{0}$ & $\begin{array}{l}0.80 \text { (species) } \\
-1.17 \text { (location) }\end{array}$ \\
\hline Species $\times$ location & $\mathbf{0}$ & $\begin{array}{r}0.04 \text { (species) } \\
0.16 \text { (location) } \\
-0.87 \text { (interaction) }\end{array}$ & $\mathbf{0}$ & $\begin{array}{r}2.55 \text { (species) } \\
-0.10 \text { (location) } \\
-2.24 \text { (interaction) }\end{array}$ & 8 & & 2 & \\
\hline
\end{tabular}

Lowest AIC values are set to 0; coefficients were added to the lowest AIC model; positive or negative coefficient values for species and location indicate higher levels of each variables for Shorea (on the path) or Macaranga (inside the forest), respectively

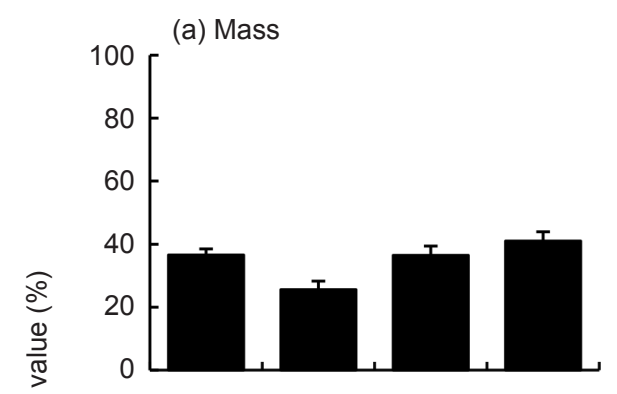

(b) Surface area

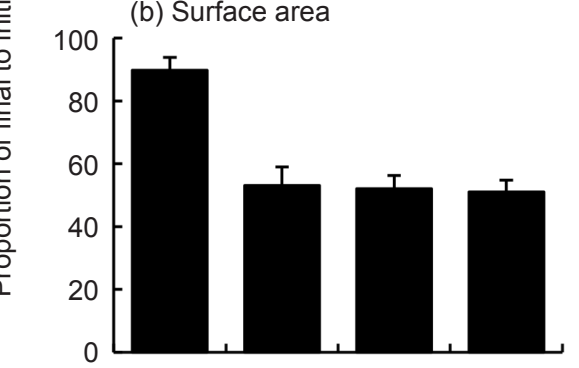

(c) Mass per area

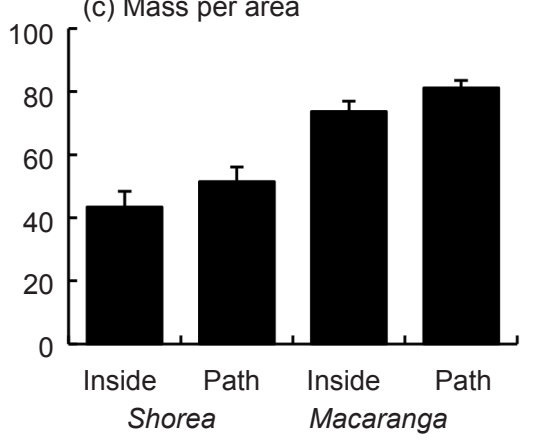

Figure 1 Proportion (\%) of initial to final value of (a) the mass $(\mathrm{g})$, (b) surface area $\left(\mathrm{cm}^{2}\right)$ and (c) mass per area $\left(\mathrm{g} \mathrm{cm}^{-2}\right)$ of Shorea macroptera and Macaranga sp. leaf litter on the path and inside the forests in the study area after 6 months; values represent means \pm standard errors

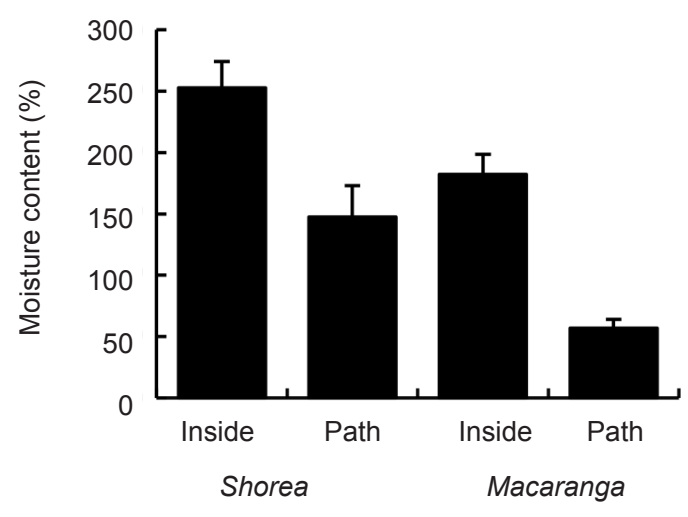

Figure 2 Moisture content (\%) of Shorea macroptera and Macaranga sp. leaf litter on the path and inside the forests in the study area at the sampling time (6 months later); values represent means \pm standard errors

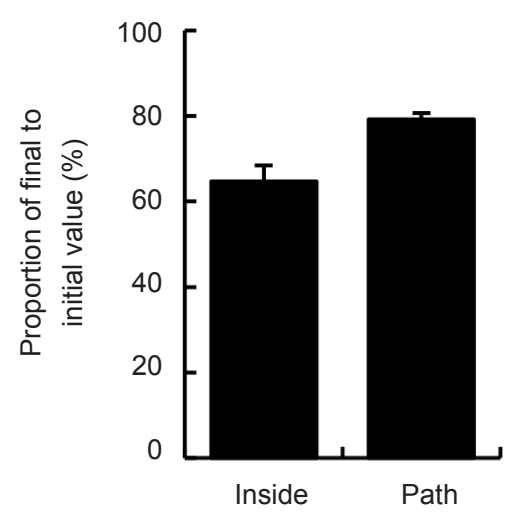

Figure 3 Proportion (\%) of final to initial value of the mass (g) of wood blocks on the path and inside the forests in the study area after 6 months; values represent means \pm standard errors 
al. (2006) reported decreased microbial activity on skid trails. In contrast to the wood blocks, the greater decomposition rates of Shorea leaf litter on the path could be attributed to greater fragmentation by biotic and abiotic processes on the path. Several studies have reported that isopods are abundant in open lands and disturbed environments (Tsukamoto \& Sabang 2005, Hassall et al. 2006, Hasegawa et al. 2014). Such litter-feeding invertebrates might be more abundant on paths created with bulldozers, resulting in greater decomposition of Shorea leaf litter. On the path, which maintained lower moisture conditions, leaf litter might also be subject to more frequent drying-and-wetting cycles, causing leaf litter to crack and split more than that inside the forest (Anderson 1973).

The decrease in the surface area of leaf litter was greater in Macaranga than in Shorea, whereas the leaf mass per area showed the opposite trend. Thus, Macaranga leaf litter was probably mainly decomposed by fragmentation, whereas Shorea leaf litter was primarily broken down by degradation processes attributed to microorganisms and leaching, in addition to fragmentation. In a tropical forest in Sarawak, a litter-bag experiment by Hirobe et al. (2004) showed that the leaf litter of three Macaranga species decomposed more rapidly than that of three Shorea species, due to the high litter quality (high phosphorus concentration and low acid-insoluble residue). Thus, the high quality of Macaranga leaf litter in the study sites had a greater effect on the preference of litter-feeding invertebrates than that of microorganisms.

\section{CONCLUSIONS}

In conclusion, the results indicated that road disturbance changed the balance between fragmentation and other degradation processes. The findings also highlighted that, in addition to measuring the loss of mass and chemical characteristics of leaf litter, assessing the loss of surface area and leaf mass per area was required to evaluate how different types of degradation processes impact leaf litter decomposition, as well as differences in litter decomposition among treatments.

\section{ACKNOWLEDGEMENTS}

The authors would like to thank Lagan $\mathrm{P}$ and the staff of the Sabah Forestry Department for supporting the study. This study was supported by the Global Environment Research Fund (F-071) of the Ministry of the Environment, Japan.

\section{REFERENGES}

Anderson JM. 1973. The breakdown and decomposition of sweet chestnut (Castanea sativa Mill.) and beech (Fagus sylvatica L.) leaf litter in two deciduous woodland soils: I. Breakdown, leaching and decomposition. Oecologia 12: 251-274.

Barlow J, Gardner TA, Ferreira LV \& Peres CA. 2007. Litter fall and decomposition in primary, secondary and plantation forests in the Brazilian Amazon. Forest Ecology Management 247: 91-97.

Bertault JG \& Sist P. 1997. An experimental comparison of different harvesting intensities with reducedimpact and conventional logging in East Kalimantan, Indonesia. Forest Ecology Management 94: 209-218.

Buckley DS, Crow TR, Nauertz EA \& Shulz KE. 2003. Influence of skid trails and haul roads on understory plant richness and composition in managed forest landscapes in Upper Michigan, USA. Forest Ecology Management 175: 509-520.

Coûteaux MM, Bottner P \& Berg B. 1995. Litter decomposition, climate and litter quality. Trends in Ecology and Evolution 10: 63-66.

Delgado JD, Arroyo NL, Arévalo JR \& Fernández-Palacios JM. 2007. Edge effects of roads on temperature, light, canopy cover, and canopy height in laurel and pine forests (Tenerife, Canary Islands). Landscape and Urban Planning 81: 328-340.

GonZÁlez G \& SEAstedt TR. 2001. Soil fauna and plant litter decomposition in tropical and subalpine forests. Ecology 82: 955-964.

GuARIgUata MR \& Dupuy JM. 1997. Forest regeneration in abandoned logging roads in lowland Costa Rica. Biotropica 29: 15-28.

Hasegawa M, Ito MT, Yoshida T et al. 2014. The effects of reduced-impact logging practices on soil animal communities in the Deramakot Forest Reserve in Borneo. Applied Soil Ecology 83: 13-21.

Hassall M, Jones DT, Taiti S, Latipi Z, Sutton SL \& Mohammed M. 2006. Biodiversity and abundance of terrestrial isopods along a gradient of disturbance in Sabah, East Malaysia. European Journal of Soil Biology 42: S197-S207.

Hirobe M, Sabang J, Bhatta BK \& Takeda H. 2004. Leaflitter decomposition of 15 tree species in a lowland tropical rain forest in Sarawak: decomposition rates and initial litter chemistry. Journal of Forest Research 9: 341-346.

Ilstedt U, Nordgren A \& Malmer A. 2006. Soil chemical and microbial properties after disturbance by crawler tractors in a Malaysian forest plantation. Forest Ecology and Management 225: 313-319.

Imai N, Seino T, Aiba S, Takyu M, Titin J \& Kitayama K. 2012. Effects of selective logging on tree species diversity and composition of Bornean tropical rain forests at different spatial scales. Plant Ecology 213: 1413-1424.

Lagan P, Mannan S \& Matsubayashi H. 2007. Sustainable use of tropical forests by reduced-impact logging 
in Deramakot Forest Reserve, Sabah, Malaysia. Ecological Research 22: 414-421.

Langner A, Titin J \& Kitayama K. 2013. The application of satellite remote sensing for classifying forest degradation and deriving above-ground biomass estimates. Pp 23-40 in Kitayama K (ed) Co-Benefits of Sustainable Forestry: Ecological Studies of a Certified Bornean Tropical Rain Forest. Springer, Tokyo.

Laurance WF, Goosem M \& LaUrance SGW. 2009. Impacts of roads and linear clearings on tropical forests. Trends in Ecology and Evolution 24: 659-669.

Makineci E, Demir M \& Yilmaz E. 2007. Long-term harvesting effects on skid road in a fir (Abies bornmulleriana Mattf.) plantation forest. Building and Environment 42: 1538-1543.

Malmer A \& Grip H. 1990. Soil disturbance and loss of infilterability caused by mechanized and manual extraction of tropical rainforest in Sabah, Malaysia. Forest Ecology and Management 38: 1-12.

Ong RC, Langner A, Imai N \& Kitayama K. 2013. Management history of the study sites: The Deramakot and Tangkulap Forest Reserves. Pp 1-21 in Kitayama K (ed) Co-Benefits of Sustainable Forestry: Ecological Studies of a Certified Bornean Tropical Rain Forest. Springer, Tokyo.

Osono T, Ishil Y, TAKedA H et AL. 2009. Fungal succession and lignin decomposition on Shorea obtusa leaves in a tropical seasonal forest in northern Thailand. Fungal Diversity 36: 101-119.

Pinard MA, BARKer MG \& TAY J. 2000. Soil disturbance and post-logging forest recovery on bulldozer paths in Sabah, Malaysia. Forest Ecology and Management 130: 213-225.

Putz FE, Sist P, Fredericksen T \& Dykstra D. 2008. Reducedimpact logging: Challenges and opportunities. Forest Ecology and Management 256: 1427-1433.
R Development Core Team. 2017. R: A Language and Environmental for Statistical Computing. R Foundation for Statistical Computing, Vienna.

Rasband WS. 2007. Image J, V. 1.37 U.S. National Institutes of Health, Bethesda, Maryland.

Sidle RC, Sasaki S, Otsuki M, Noguchi S \& Rahim Nik A. 2004. Sediment pathways in a tropical forest: effects of logging roads and skid trails. Hydrological Processes 18: 703-720.

Slik JWF, Kessler PJA \& VAn Welzen PC. 2003. Macaranga and Mallotus (Euphorbiaceae) as indicators for disturbance in the mixed lowland dipterocarp forest of East Kalimantan (Indonesia). Ecological Indicators 2: 311-324.

Swift MJ, Heal OW \& Anderson JM. 1979. Decomposition in Terrestrial Ecosystems. Blackwell Scientific Publications, Oxford.

Tsukamoto J \& Sabang J. 2005. Soil macro-fauna in an Acacia mangium plantation in comparison to that in a primary mixed dipterocarp forest in the lowlands of Sarawak, Malaysia. Pedobiologia 49: 69-80.

Uhl C, Jordan C, Clark K, Clark H \& Herrera R. 1982. Ecosystem recovery in Amazon caatinga forest after cutting, cutting and burning, and bulldozer clearing treatments. Oikos 38: 313-320.

VAsconcelos HL, Vilhena JMS \& CaLiRi GJA. 2000. Responses of ants to selective logging of a central Amazonian forest. Journal of Applied Ecology 37: 508-514.

WALLIN TR \& HARDEN CP. 1996. Estimating trail-related soil erosion in the humid tropics: Jatun Sacha, Ecuador, and La Selva, Costa Rica. Ambio 25: 517-522.

WARTON DI \& HuI FKC. 2011. The arcsine is asinine: the analysis of proportion in ecology. Ecology 92: 3-10.

Yamashita T \& TAKEDA H. 1998. Decomposition and nutrient dynamics of leaf litter in litter bags of two mesh sizes set in two dipterocarp forest sites in Peninsular Malaysia. Pedobiologia 42: 11-21. 